\title{
COMPUTATIONAL AND NUMERICAL ANALYSIS OF RADIATOR USING DIFFERENT NANOFLUIDS AS COOLANT WITH DIFFERENT STRUCTURE OF RADIATOR TUBE
}

\author{
Devakannan Vaidhilingam \\ Department of Metallurgical engineering \\ Government College of Engineering, Salem, Tamilnadu, India
}

\begin{abstract}
As an engineer we would like to establish our theoretical knowledge in developing a spiral flow radiator using Nanofluids as coolant. A radiator is a primary part of an automotive to reduce the heat of the coolant circulated in the engine with help of air flow passing through it during the movement of the vehicle. These radiators have few troubles in achieving its maximum performance level as like failure of thermostat, clotting of tubes due to presence of alkaline content in coolants, performance problems of radiator due to overheating. The project is mainly focused on utilizing the Nanofluids as coolant in order to improve the performance of the radiator. The properties of Nanofluids have been studied and the various factors such as material density, specific heat and thermal conductivity are taken into consideration. The radiator analysis is categorized into two broad categories namely spiral flow analysis and straight flow analysis radiator with fins. The radiator tube is designed and the Nanofluids are assigned and the analysis is carried out in ANSYS 15.0. The static pressure values and vector flows are obtained. From obtained results we can conclude which Nanofluids have better efficiency and performance.
\end{abstract}

Keywords: Radiator performance; Nanofluids; Spiral tubes; straight tube with fins;

\section{INTRODUCTION}

A Radiator is a type of heat exchanger. It is designed to transfer heat from the hot coolant that flows through it to the air blown through it by the fan. Most modern cars use aluminum radiators. These radiators are made by brazing thin aluminum fins to flattened aluminum tubes. The coolant flows from the inlet to the outlet through many tubes mounted in a parallel arrangement. The fins conduct the heat from the tubes and transfer it to the air flowing through the radiator.

The tubes sometimes have a type of fin inserted into them called a turbulator, which increases the turbulence of the fluid flowing through the tubes. If the fluid flowed very smoothly through the tubes, only the fluid actually touching the tubes would be cooled directly. The amount of heat transferred to the tubes from the fluid running through them depends on the difference in temperature between the tube and the fluid touching it. So if the fluid that is in contact with the tube cools down quickly, less heat will be transferred. By creating turbulence inside the tube, all of the fluid mixes together, keeping the temperature of the fluid touching the tubes up so that more heat can be extracted, and all of the fluid inside the tube is used effectively.

Radiators usually have a tank on each side, and inside the tank is a transmission cooler. In the picture above, you can see the inlet and outlet where the oil from the transmission enters the cooler. The transmission cooler is like a radiator within a radiator, except instead of exchanging heat with the air, the oil exchanges heat with the coolant in the radiator.

\section{Principle of Radiator}

Radiators are cooling devices fitted in automobiles. These devices primarily maintain the engine temperature at an optimal level. Automobile radiators should not be confused with home radiators that are used for heating homes. Radiators are usually fabricated from cast iron, and they comprise a series of pipes through which a coolant (water or synthetic coolant) circulates.

The working principle of a car radiator is as follows:

$>$ A pumping system pushes the normal temperature coolant from the radiator towards engine.

$>$ A running engine produces a large amount of heat, which is absorbed by the coolant eventually, the engine temperature falls down. This heated coolant is again pumped back to the radiator.

$>$ Once the hot coolant reaches the radiator, it circulates through a series of pipes of the radiator.

$>$ Air surrounding the radiator absorbs this heat and brings down the temperature of the heated coolant

$>$ The procedure continues as long as the vehicle is running.

$>$ In the absence of the radiator, the engine will cease to function due to overheating. 


\section{Function Of Coolants In The Radiator}

Most vehicles break down when the coolant in the radiators is used up. Earlier, water was used as cooling agent in automobiles. Now, synthetic coolants are widely available in the market. However, during winter, water freezes in the radiators, thus leading to the bursting of radiator pipes. Synthetic coolants have antifreeze in them, thus they do not freeze when the surrounding temperatures are low. Synthetic coolants last longer (as compared to water).

\section{Nanofluids}

The coolant used in automobile radiators must have good thermal properties such as coolant have high thermal conductivity, low freezing point and high boiling point. Conventional coolants used in radiators are water or mixture of water and Ethylene glycol with certain additives, since these conventional coolant have very low thermal conductivity hence heat transfer rate from radiator is very low due to which we need to increase the surface area to get required heat transfer rate, this makes the radiator bulky, increase the material cost and also occupies large space in automobile, hence aesthetically vehicle not looking good. From above discussion we conclude that there is a need of new type of coolant in automotive cooling system. From the last decade researchers try to use Nanofluids as a coolant in automotive radiator and very good results are obtained from their work. As we know that metals or metal oxides have good thermal conductivity compared to liquids so if we mix the Nanosized metals or metal oxides particles in base fluid then the resultant mixture expected to have larger thermal conductivity than the base fluid hence we get a good heat transfer rate. Due to the use of Nanosized particles the problem related to sedimentation and pressure drop is negligible and hence Nanofluids is able to use as a coolant in automobile radiators.

\section{Advantages Of Radiators}

Low maintenance:

While there are some instances where radiators will need to be serviced by a professional, they tend to be relatively low maintenance. This is because they are hooked up to your home's plumbing system and utilize your water heater to produce heat: they themselves have very little internal components that will need to be checked up on or replaced.

Reliable:

In a similar vein to the above point, radiators are extremely durable and reliable, usually being made out of porcelain, cast iron, or ceramic, which means that they can withstand a great deal of wear and tear without becoming damaged. In addition, due to the fact that they have very few moving parts and no dedicated heating element, they are unlikely to suffer mechanical breakdowns and stop functioning even after years of use.

Conductivity:
Another major advantage of radiators is the fact that ceramic, cast iron, and other materials used to construct them will hold on to heat for an extended period of time, which means that your radiator will continue to heat up the room that it is installed in even after they have been turned off.

\section{Shortcomings of Radiators}

Noise: A key disadvantage associated with radiators is the fact that they can be noisy while operating, which is usually caused by some sort of air that is caught in the pipes. This can take the form of squealing, banging, or other knocking sounds.

Needs Ventilation: In order for a radiator to properly work, it needs an adequate amount of air flow in the room that it is installed in. Otherwise, the heat from the unit will simply sit around the unit, which can reduce the comfort levels within your home and create drafts and cold spots.

Hot: Another major downside of radiators, especially if you have small children or pets in the house, is the fact that they can grow extremely hot to the touch while working. This is an important safety consideration to keep in mind, as burnt hands or paws (or even drapes and blankets that catch fire) are an important safety consideration.

\section{PROBLEM FORMULATION}

Great efforts have been spent to improve the thermal efficiency of a number of processes with mixed success until the recent emergence of a promising new class of Nano coolants with a liquid component such as water mixed with Nanoparticles started to make their way into a myriad of engineering applications.

$>$ Although they are expected to provide substitutes of conventional coolants in the near future, a number of improvements are still to be made.

> Attempts are still being made on one hand to reduce the equipment's size and increase the thermal exchange surface by using fins, and on the other hand to increase the thermal conductivity of fluid exchangers.

> Improvements in Nanotechnology have enhanced our abilities to synthesize Nano scale materials, such as different types of Nanoparticles including non metallic, carbon based and metallic ones, which have started to be used in conventional fluids such as water, ethylene glycol and oil, creating a new class of fluids called Nanofluids.

$>$ These Nanofluids have been shown to have enhanced thermal properties and potential applications in various fields such as medicine, electronics and transportation.

> From various problem statements referred we carried out the Analysis of cross sectional Radiator tube using different Nanofluids.

$>$ Similarly the analysis has been carried out for straight tube for different Nanofluids.

$>$ The results are compared and the best suitable material for different flows has been found 


\section{Methodology}

This chapter provides a comprehensive diagrammatic view of the project methodology of the project work.

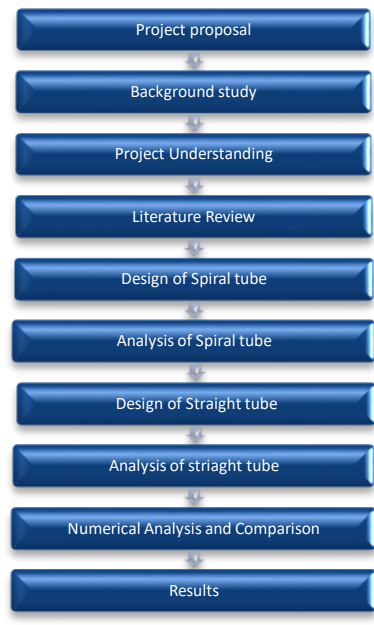

.Fig. 2.1 Methodology

\section{Design of Spiral Tube Radiator}

The new design of spiral radiator tube is created with the help of Catia V5 software as shown in fig 2.3. Meshing is the process in which geometry is spatially discretized into elements and nodes. Meshing of model consist of tetrahedral elements. Number of elements $=15,364$ and Number of nodes $=$ 29,436 as shown in fig. 2.3 .

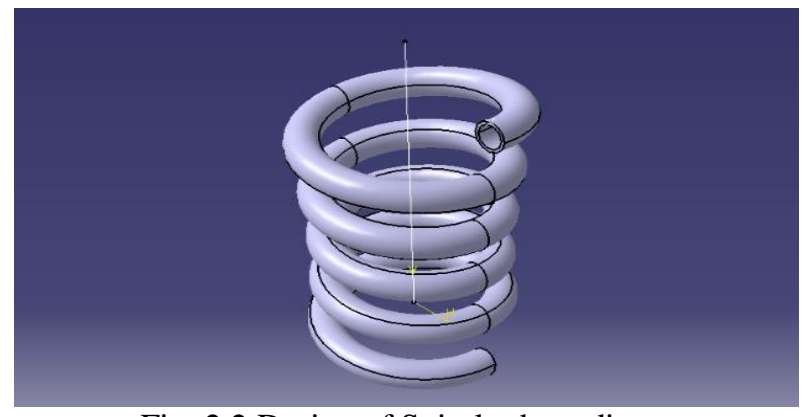

Fig. 2.2 Design of Spiral tube radiator

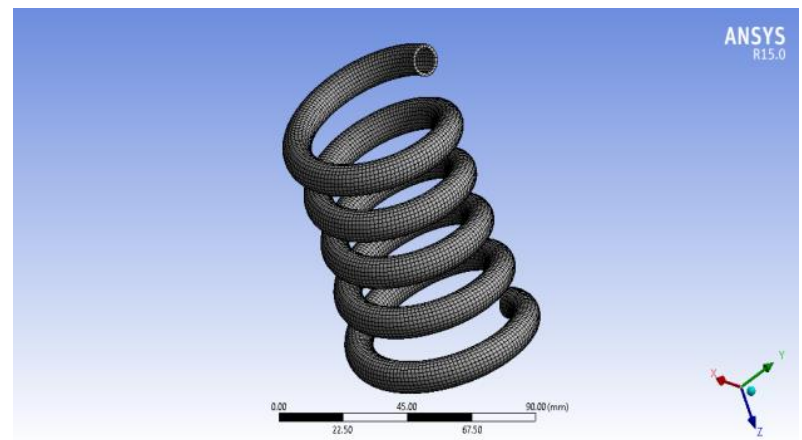

Fig. 2.3 Coarse Mesh of Spiral tube radiator
Design of Straight Tube Radiator

Number of elements $=30415$ and

Number of Nodes $=10643$

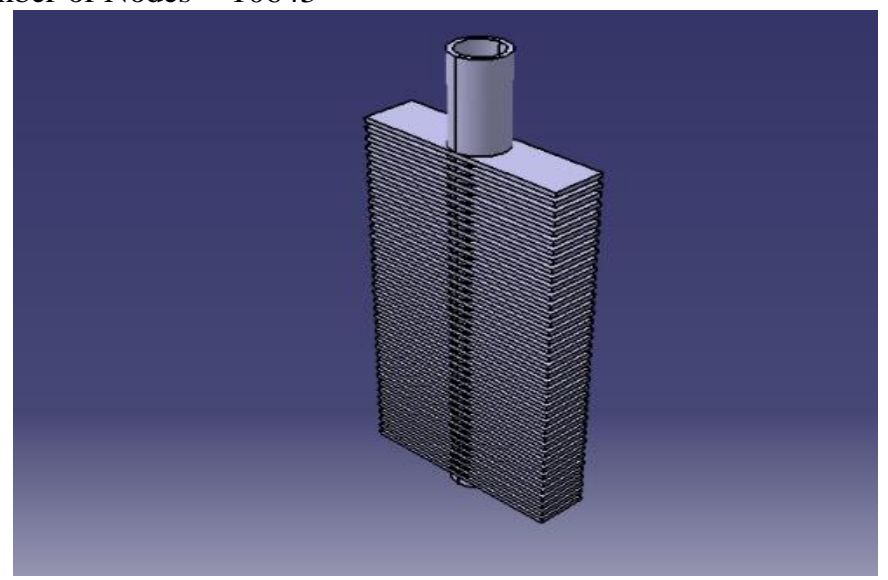

Fig. 2.4 Design of Straight tube radiator

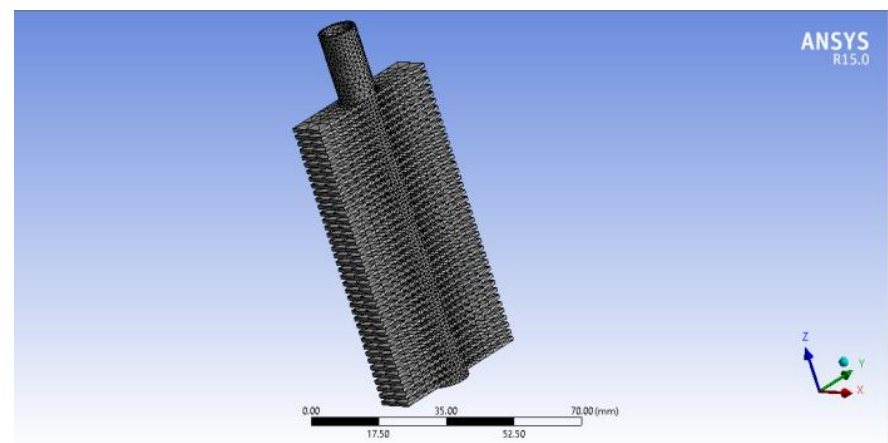

Fig. 2.5 Coarse Mesh of Straight tube Radiator

\section{PROCESS SELECTION}

The various process parameters of the radiator are

$\checkmark$ Radiator tube types.

$\checkmark$ Radiator Depth.

$\checkmark$ Types of Nanofluids used.

\section{Radiator Tube Types}

Radiators are classified according to the direction that the coolant flows through them. The two types of radiators are the down flow and cross flow. The down flow radiator has the coolant tanks on the top and bottom and the core tubes run vertically. Hot coolant from the engine enters the top tank. The coolant flows downward through the core tubes. After cooling, coolant flows out the bottom tank and back into the engine. The cross flow radiator is a design that has the tanks on the sides of the core. The core tubes are arranged for horizontal coolant flow. The tank with the radiator cap is normally the outer tank. A cross flow radiator can be shorter, allowing for a lower vehicle hood. 


\section{Radiator Depth}

The effect of heat transfer performance depends on radiator depth. The Radiator length alone is not sufficient to generate heat transfer performance. To achieve heat transfer performance of design, we must increase number of fins per row.

\section{Types of coolants used}

New classes of coolants are Nanofluids which consist of a carrier liquid, such as water, dispersed with tiny Nanoscale particles known as nano particles. Purpose-designed nano particles of e.g. $\mathrm{CuO}$, alumina, titanium dioxide, carbon nano tubes, silica, or metals (e.g. copper or silver nano rods) dispersed into the carrier liquid enhance the heat transfer capabilities of the resulting coolant compared to the carrier liquid alone. The enhancement can be theoretically as high as $350 \%$. The experiments however did not prove so high thermal conductivity improvements, but found significant increase of the critical heat flux of the coolants.

In this project we had used Nanofluids as secondary coolant. Thus the Nanofluids were analyzed by using them in spiral flow tube. Thermal conductivity, Specific heat capacity and material density of various Nanofluids are mentioned in the table 3.1. The Various Nanofluids analyzed are mentioned below.

$>$ Aluminium Oxide

$>$ Beryllium Oxide

$>$ Calcium Oxide

$>$ Copper Oxide

$>$ Copper Sulphate

$>$ Ethylene Glycol

$>$ Magnesium Sulphate

$>$ Magnesium oxide

$>$ Manganese Oxide

$>$ Silicon Carbide

$>$ Silicon Chloride

$>$ Tin Oxide

$>$ Titanium Oxide

$>$ Vinyl Chloride

Table3.1 Properties of Nanofluids

\begin{tabular}{|c|c|c|c|}
\hline Material & $\begin{array}{c}\text { Thermal } \\
\text { Conductiv } \\
\text { ity } \\
\left(\mathbf{W} / \mathbf{M}^{2} \mathbf{k}\right)\end{array}$ & $\begin{array}{c}\text { Specific } \\
\text { Heat } \\
\text { Capacity } \\
\text { ( J/Kg.K) }\end{array}$ & $\begin{array}{c}\text { Material } \\
\text { Density }\left(\mathrm{Kg} / \mathbf{M}^{3}\right)\end{array}$ \\
\hline Aluminium Oxide & 9.205 & 628 & 5900 \\
\hline Beryllium Oxide & 255.22 & 1046 & 2900 \\
\hline Calcium Oxide & 13.807 & 753 & 3030 \\
\hline Copper Oxide & 17.991 & 536 & 6500 \\
\hline Copper Sulphate & 2.092 & 753 & 3606 \\
\hline Ethylene Glycol & 0.425 & 3287 & 1056 \\
\hline Magnesium Sulphate & 2.51 & 1255 & 2660 \\
\hline Magnesium Oxide & 69.036 & 921 & 3580 \\
\hline Manganese Oxide & 69.036 & 921 & 3580 \\
\hline Silicon Carbide & 21.757 & 678 & 2700 \\
\hline Silicon Chloride & 45.354 & 720 & 1480 \\
\hline Tin Oxide & 31.38 & 343 & 5560 \\
\hline
\end{tabular}

\begin{tabular}{|l|c|c|c|}
\hline Titanium Oxide & 13.389 & 686 & 4250 \\
\hline Vinyl Chloride & 27.82 & 478 & 911 \\
\hline
\end{tabular}

\section{Computational Analysis of Spiral Tube:}

\section{Aluminium Oxide}

$\mathrm{Al}_{2} \mathrm{O}_{3}$ is an electrical insulator but has a relatively high thermal conductivity. Aluminium oxide is insoluble in water. In its most commonly occurring crystalline form, called corundum or $\alpha$-aluminium oxide, its hardness makes it suitable for use as an abrasive and as a component in cutting tools. Aluminium oxide is responsible for the resistance of metallic aluminium to weathering. Metallic aluminium is very reactive with atmospheric oxygen, and a thin passivation layer of aluminium oxide (4 $\mathrm{nm}$ thickness) forms on any exposed aluminium surface.

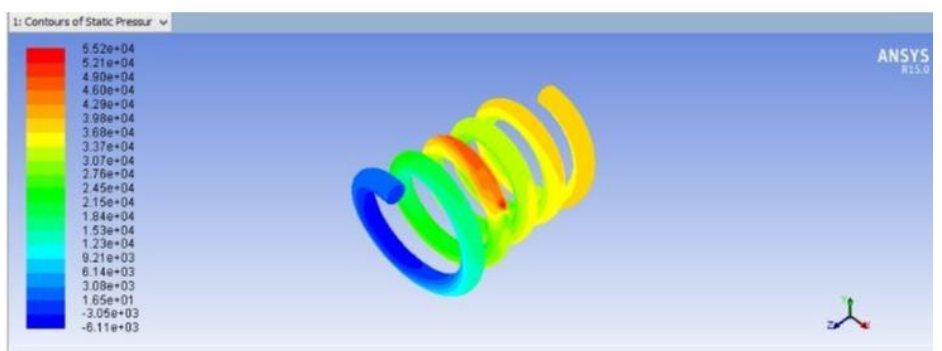

Fig. 3.1 Contour of Static pressure of $\mathrm{Al}_{2} \mathrm{O}_{3}$ Nanofluids

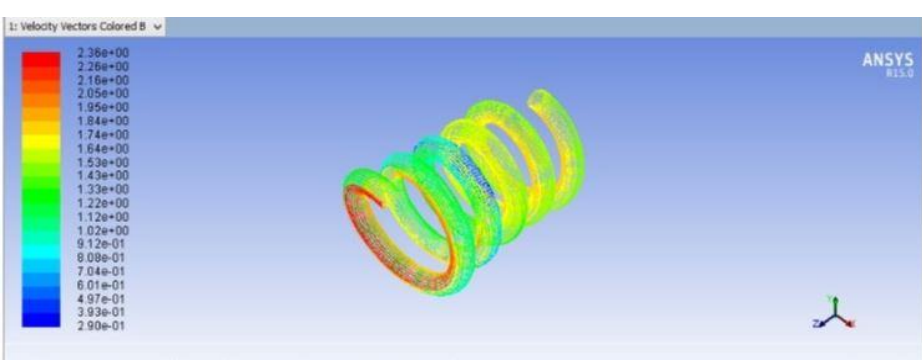

Fig. 3.2 Velocity Vector of $\mathrm{Al}_{2} \mathrm{O}_{3}$ Nanofluids

\section{Computational Analysis Of Straight Tube With Fins Beryllium Oxide}

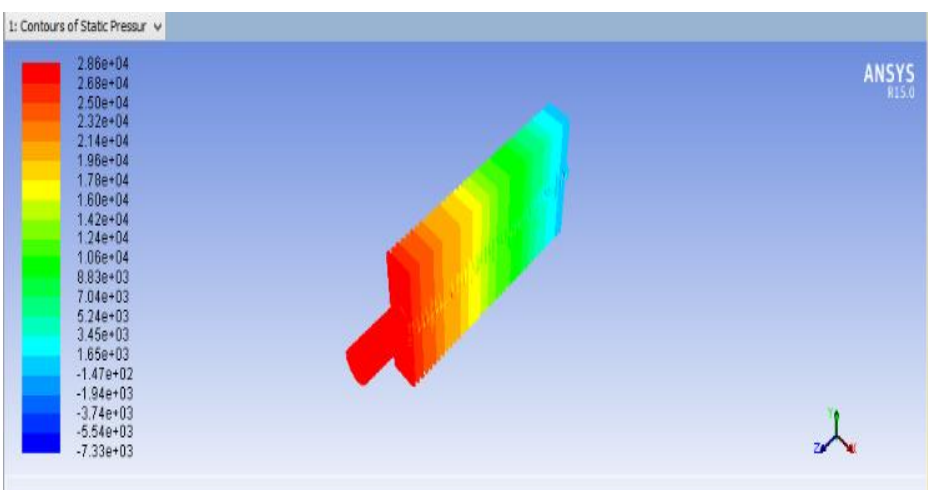

Fig. 3.3 Contour of Static pressure of BeO Nanofluids 


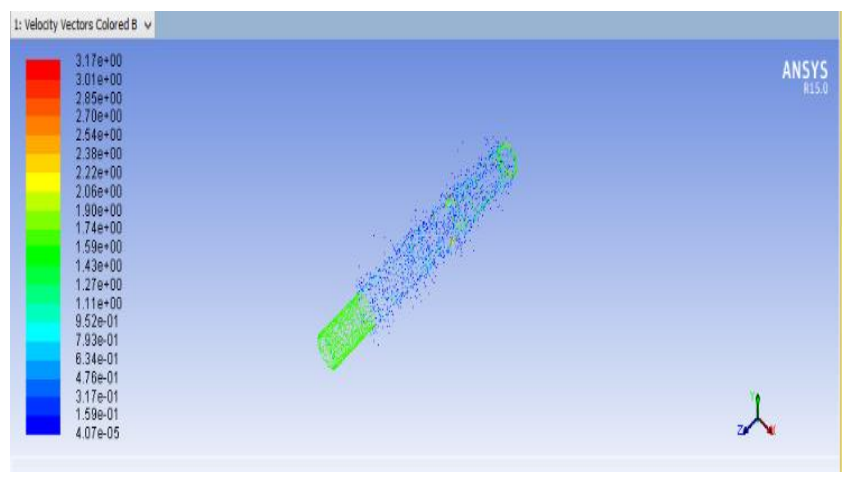

Fig. 3.4 Velocity vector of BeO Nanofluids

\section{Numerical Analysis For Nanofluids:}

The heat transfer rate, $\mathrm{Q}$, is also function of the radiator itself and is expressed by,

$$
\begin{gathered}
\mathrm{Q}=\mathrm{m} \mathrm{C}_{\mathrm{p}} \mathrm{D}_{\mathrm{T}} \\
\mathrm{Q}=\mathrm{U}_{\mathrm{o}} \times \mathrm{A}_{\mathrm{o}} \times \mathrm{LMTD}
\end{gathered}
$$

The overall heat transfer coefficient is a function of the inside \& outside heat transfer coefficients of heat transfer and conduction,

$$
1 / \mathrm{U}_{\mathrm{o}}=1 / \mathrm{h}_{\mathrm{o}}+\mathrm{A}_{\mathrm{o}} /\left(\mathrm{h}_{\mathrm{i}} \mathrm{A}_{\mathrm{i}}\right)+\mathrm{R}
$$

Engine heat rejection to the coolant at $2000 \mathrm{RPM}=45 \mathrm{~kW}$

If the vehicle has an automatic transmission and it is cooled by an in tank cooler, the transmission heat loss must be added.

Automatic transmission heat rejection $\quad=8 \mathrm{~kW}$

Total heat rejection

$$
=53 \mathrm{~kW}
$$

Ambient temperature

$$
=20^{\circ} \mathrm{C}
$$

Air temperature into radiator,

$\mathrm{T}_{\text {air }}=20^{\circ} \mathrm{C}$

Air temperature out of radiator,

$\mathrm{T}_{\mathrm{ao}}=80^{\circ} \mathrm{C}$

Coolant temperature into radiator, $\mathrm{T}_{\mathrm{ci}}=90^{\circ} \mathrm{C}$

Max. Coolant temperature out of the radiator, $\mathrm{T}_{\mathrm{co}}=70^{\circ} \mathrm{C}$

Radiator dimensions

Width, $\mathrm{B}=750 \mathrm{~mm}$

Height, $\mathrm{H}=550 \mathrm{~mm}$

Depth, $\mathrm{T}=20 \mathrm{~mm}$

$$
\begin{aligned}
& \mathrm{Q}^{*}=\frac{\text { Total heat re jection }}{\text { (coolant temperature into radiator }- \text { Air temperature into radiator })} \\
& \mathrm{Q}^{*}=58 /((90-20) \times(0.3623)) \\
& \mathrm{Q}^{*}=22.49442 \mathrm{kCal} / \mathrm{hr} \mathrm{m}^{2 \circ} \mathrm{C}
\end{aligned}
$$

\section{Radiator Effectiveness}

$$
\begin{aligned}
& \mathrm{E}_{\mathrm{rad}}=(\text { Tao-Tair }) /(\text { Tci-Tco }) \\
& \mathrm{E}_{\mathrm{rad}}=(80-20) /(90-20)=85.7 \%
\end{aligned}
$$$$
(\text { Tco }- \text { Tci })=53 * 3600 / 110 * 60 * 3.287=8^{\circ} \mathrm{C}
$$$$
\mathrm{Tco}=90-8=82^{\circ} \mathrm{C}
$$

$\mathrm{LMTD}=(70-20) /(\ln (70 / 20))$

$$
\begin{gathered}
\mathrm{LMTD}=40^{\circ} \mathrm{C} . \\
\mathrm{Q}=53 \mathrm{~kW}
\end{gathered}
$$

$$
\mathrm{A}_{\mathrm{o}}=10.38 \text { sq. } \mathrm{m}
$$

Outside radiator surface $\mathrm{U}_{\mathrm{o}}=\mathrm{Q} /\left(\mathrm{A}_{\mathrm{o}} *\right.$ LMTD $)$

$$
\begin{gathered}
\mathrm{U}_{\mathrm{o}}=53 /(10.38 \times 40) \\
\mathrm{U}_{\mathrm{o}}=0.1276 \mathrm{~kW} / \mathrm{m}^{2}{ }^{\circ} \mathrm{C}
\end{gathered}
$$

Inside heat transfer coefficient can be calculated with the help of Dittus \& Boelter equation,

$\mathrm{Nu}=0.023 *(\operatorname{Re})^{0.8}(\operatorname{Pr})^{0.3}$

$\mathrm{Nu}=$ hi $\times \mathrm{D}_{\mathrm{h}} / \mathrm{K}$

$$
\mathrm{h}_{\mathrm{i}} \times \mathrm{D}_{\mathrm{h}} / \mathrm{k}=0.023 *(\mathrm{Re})^{0.8}(\operatorname{Pr})^{0.3}
$$

$\mathrm{D}_{\mathrm{h}}=4 *$ tube cross section / wetted perimeter

$$
\begin{gathered}
\mathrm{D}_{\mathrm{h}}=0.00174 \mathrm{~m} \\
\sigma=1015 \mathrm{Kg} / \mathrm{m}^{3} \\
\mu=0.00063 \mathrm{~N} . \mathrm{s} / \mathrm{m} \\
\mu=6.31 \times 10-4 \mathrm{~kg} / \mathrm{m} . \mathrm{s} \\
\mathrm{k}=0.42 \mathrm{~W} / \mathrm{m}^{\circ} \mathrm{C} \\
\mathrm{C}_{\mathrm{p}}=3287 \mathrm{~J} / \mathrm{Kg}^{\circ} \mathrm{C} \\
\mathrm{V}=1.62 \mathrm{~m} / \mathrm{s}
\end{gathered}
$$

Reynolds Number Re $=\mathrm{Dh} \times \mathrm{V}$ x $\sigma / \mu$

$\operatorname{Re}=(0.00174 \times 1.62 \times 1015) / 0.00063$

$$
\operatorname{Re}=4541.4
$$

Prandtl Number, $\operatorname{Pr}=\mu \times \mathrm{C}_{\mathrm{p}} / \mathrm{k}$

$\operatorname{Pr}=0.00063 * 3287 / 0.42$

$$
\operatorname{Pr}=4.93
$$

Now inside heat transfer coefficient can be calculated, $\mathrm{h}_{\mathrm{i}}=[(0.023 \times 0.42) / 0.0033] \times(9086) 0.8 \times(6.38) 0.3$

$$
\mathrm{h}_{\mathrm{i}}=7551 \mathrm{w} / \mathrm{m}^{2}{ }^{\circ} \mathrm{C}
$$

An extended surface heat exchanger inside \& outside coefficient per unit airside area should be about the same for good exchanger design.

$$
1 / \mathrm{h}_{\mathrm{o}}=\mathrm{A}_{\mathrm{o}} /\left(\mathrm{A}_{\mathrm{i}} \times \mathrm{h}_{\mathrm{i}}\right)
$$

The outside coefficient may now to be determined from the equation,

$$
\begin{gathered}
1 / \mathrm{h}_{\mathrm{o}}=1 / \mathrm{U}_{\mathrm{o}}-\mathrm{A}_{\mathrm{o}} /\left(\mathrm{h}_{\mathrm{i}} \times \mathrm{A}_{\mathrm{i}}\right)-\mathrm{R} \\
\mathrm{A}_{\mathrm{i}}=\text { Inside heat transfer } \\
\text { Area }=1.16 \mathrm{~m}^{2}
\end{gathered}
$$

$\mathrm{R}$ is metal resistance, assumed to be negligible:

$$
\mathrm{h}_{\mathrm{o}}=168 \mathrm{w} / \mathrm{m}^{2}{ }^{\circ} \mathrm{C}
$$

\section{CONCLUSION}

From the obtained results in computational and numerical analysis the following materials Ethylene Glycol, Copper Oxide, Tin oxide can be used as Nanofluids to improve the performance of radiator. For spiral tube the preferable Nanofluids are Ethylene Glycol and Aluminium Oxide. For Straight tube the preferable Nanofluids are Beryllium Oxide and Calcium Oxide. 
Published Online April 2020 in IJEAST (http://www.ijeast.com)

Table 4.1 Heat Loss Comparison

\begin{tabular}{|c|c|c|c|c|}
\hline S.No & Material Name & $\mathbf{C p}$ & $\begin{array}{c}\mathbf{h}_{\mathbf{i}}\left(\mathbf{W} / \mathbf{m}^{\mathbf{2}}\right. \\
\left.{ }^{\mathbf{o}} \mathbf{C}\right)\end{array}$ & $\begin{array}{c}\mathbf{h}_{\mathbf{o}}\left(\mathbf{W} / \mathbf{m}^{\mathbf{2}}\right. \\
\left.{ }^{\circ} \mathbf{C}\right)\end{array}$ \\
\hline 1 & Berylliyum Oxide & 1046 & 9328 & 109 \\
\hline 2 & Calcium Oxide & 753 & 8431.2 & 121.6 \\
\hline 3 & Copper Oxide & 536 & 7663 & 133.8 \\
\hline 4 & Copper Sulphate & 783 & 8230 & 118 \\
\hline 5 & Ethylene glycol & 3287 & 7511 & 168 \\
\hline 6 & $\begin{array}{c}\text { Magnesium } \\
\text { Oxide }\end{array}$ & 941 & 9124 & 120 \\
\hline 7 & Manganese Oxide & 921 & 8976 & 114.2 \\
\hline 8 & $\begin{array}{c}\text { Magnesium } \\
\text { Sulphate }\end{array}$ & 1255 & 9817.026 & 104 \\
\hline 9 & Silicon carbide & 678 & 8190 & 125 \\
\hline 10 & Tin oxide & 343 & 6674.4 & 153.6 \\
\hline 11 & Titanium oxide & 686 & 8219.5 & 124.75 \\
\hline
\end{tabular}

Table 4.2 Static pressure values for spiral flow tube

\begin{tabular}{|c|c|c|}
\hline S.No & Name & $\begin{array}{c}\text { Static pressure values } \\
\left(\mathbf{N} / \mathbf{m m}^{2}\right)\end{array}$ \\
\hline 1 & Aluminium Oxide & $5.53 \times 10^{4}$ \\
\hline 2 & Beryllium Oxide & $2.71 \times 10^{4}$ \\
\hline 3 & Calcium Oxide & $1.59 \times 10^{4}$ \\
\hline 4 & Copper Oxide & $1.19 \times 10^{5}$ \\
\hline 5 & Copper Sulphate & $3.37 \times 10^{4}$ \\
\hline 6 & Ethylene glycol & $9.83 \times 10^{3}$ \\
\hline 7 & Magnesium Sulphate & $2.48 \times 10^{4}$ \\
\hline 8 & Magnesium Oxide & $3.35 \times 10^{4}$ \\
\hline 9 & Manganese Oxide & $5.06 \times 10^{4}$ \\
\hline 10 & Silicon Carbide & $1.49 \times 10^{4}$ \\
\hline 11 & Silicon Chloride & $1.05 \times 10^{4}$ \\
\hline 12 & Tin Oxide & $5.21 \times 10^{4}$ \\
\hline 13 & Titanium Oxide & $3.55 \times 10^{4}$ \\
\hline 14 & Vinyl Chloride & $1.03 \times 10^{2}$ \\
\hline
\end{tabular}

Table 4.3 Static pressure for straight flow tube with Fins

\begin{tabular}{|c|c|c|}
\hline S.No & Name & $\begin{array}{c}\text { Static pressure } \\
\text { values }\left(\mathrm{N} / \mathrm{mm}^{2}\right)\end{array}$ \\
\hline 1 & Beryllium oxide & $2.86 \times 10^{4}$ \\
\hline
\end{tabular}

\begin{tabular}{|c|c|c|}
\hline 2 & Calcium oxide & $3.30 \times 10^{1}$ \\
\hline 3 & Copper oxide & $6.33 \times 10^{4}$ \\
\hline 4 & Copper sulphate & $3.23 \times 10^{1}$ \\
\hline 5 & Ethylene glycol & $3.24 \times 10^{1}$ \\
\hline 6 & Silicon carbide & $3.14 \times 10^{1}$ \\
\hline
\end{tabular}

Comparison Charts:

\section{hi $\left(\mathrm{W} / \mathrm{m}^{2} \mathrm{oC}\right)$}

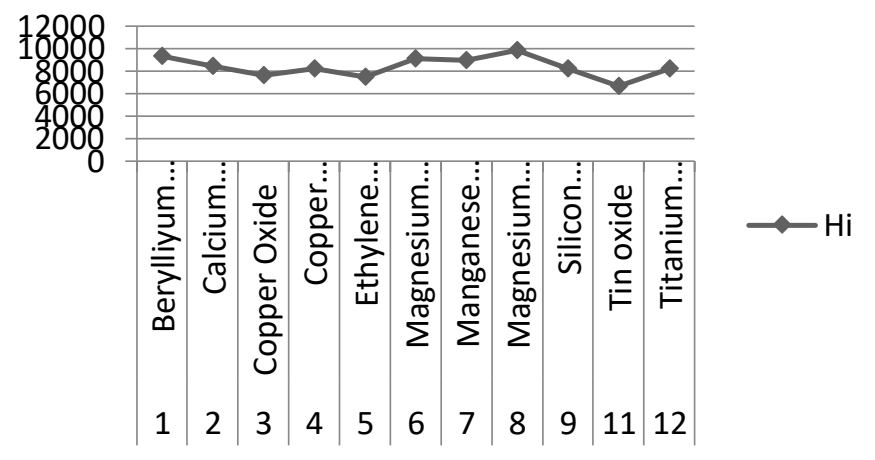

Fig. 4.1 Heat Loss in Inner Surface

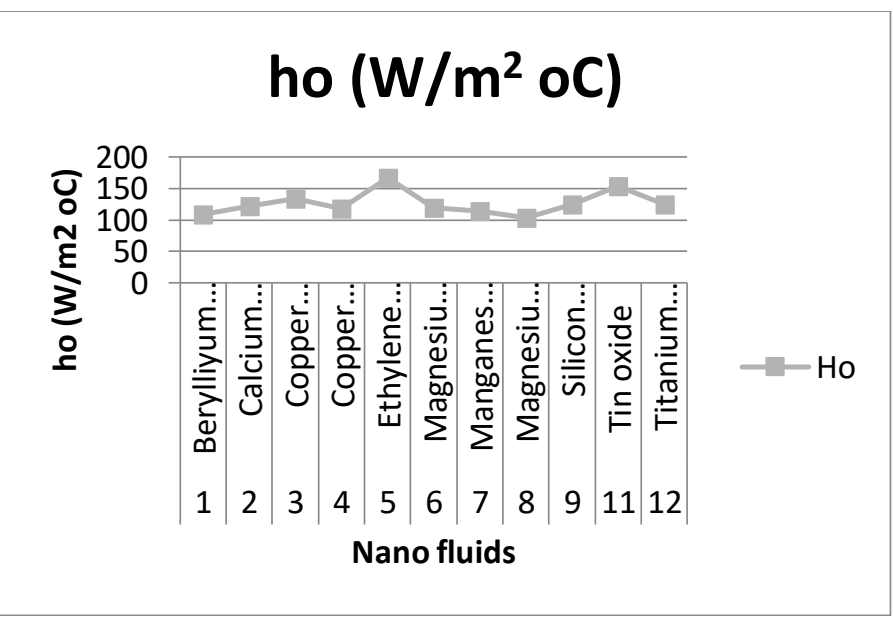

Fig. 4.2 Heat loss in outer surface

\section{ACKNOWLEDGEMENT}

With genuine humanity, we obediently thankful to god almighty praise and glorious to him, for all his uncountable bounties and guidance, without which this work would have never been a reality 
I am highly indebted to the management of Government College of Engineering, Salem for their guidance and constant support and providing necessary facilities regarding our project

I extend our sincere thanks to Miss.T.Sowmia Devi, for his valuable guidance which helped us in this project work.

My heart-felt thanks to all teaching and non-teaching staff members of the Department of Metallurgical Engineering and to all those who have directly or indirectly extended their help to me.

\section{REFERENCES}

[1] Maïga, S. E. B., Nguyen, C. T., Galanis, N. and Roy,G. (2004). "Heat transfer behaviours of nanofluids in a uniformly heated tube." Superlattices and Microstructures, $35,543-557$.

[2] H.Sayehvand, A.Habibzadeh, A.Mekani k (2012) " Cfd Analysis Of Natural Convection Heat Transfer In A Square Cavity With Partitions Using $\mathrm{Al}_{2} \mathrm{O}_{3}$ Nanofluid" International Journal of NanoDimension 2(3): 191-200.

[3] Vinod M. Angadi, R. Nagaraj, Dr. O. D. Hebbal (2014) "Cfd Analysis Of Heat Transfer Enhancement Of A Car Radiator Using Nanofluid As A Coolant" International Journal of Engineering Research \& Technology (IJERT) Vol. 3 Issue 8.

[4] Ahmad Fakheri, (2014) "Heat Exchanger Efficiency", Journal of Heat Transfer, Vol.129

[5] Akhilnandh Rameshx, M. Jaya Arun Prasanth, A.Kirthivasan, M.Suresh (2015) "Heat Transfer Studies on Air Cooled Spiral Radiator with Circumferential Fins" International Conference on Computational Heat and Mass Transfer, $333-339$.

[6] Parashurama M, Dr. Dhananjaya D, Naveena Kumar R (2015) "Experimental Study of Heat Transfer in a Radiator using Nanofluid" IJEDR-Volume 3,Issue 2 ISSN: 23219939.

[7] R. Paul Linga Prakash, M. Selvam, A. Alagu Sundara Pandian, S. Palani and K. A. Harish (2016) "Design and Modification of Radiator in I.C. Engine Cooling System for Maximizing Efficiency and Life" Indian Journal of Science and Technology, Vol 9(2), DOI: 10.17485/ijst/2016/V9i2/ 85810.

[8] V.Niveditha, Dr. S. Sunil Kumar Reddy (2016) "Thermal Analysis of Radiator with Different NanoFluids" International Journal for Research in Applied Science \& Engineering Technology (IJRASET) Volume 4 Issue IX, ISSN: 2321-9653.

[9] Rajkumar Bodakuntla, Raju Rao Perala, Srinivasalu.P (2016) "Computer Simulations Of Natural Convection Of Single Phase Nanofluids In Simple Enclosures" International Journal of Innovative science, Engineering \& Technology, Vol.3 Issue 8.
[10] M.Dhanunjaiah (2017) "Design \& Analysis of Radiator" International conference on recent innovations in science, engineering and management.ISBN:978-93-86171-53-5.

[11] K. Chinnarasu, M. Ranjithkumar, P. Lakshmanan, K. B. Hariharan, N. K.Vigneshwaran and S. Karan (2018) " Analysis of Varying Geometri Structures of Fins using Radiators" Journal of Applied Fluid Mechanics, Vol. 11, Special Issue, pp. 115-119.

[12] Devendra Vashist (2014) "Some Studies on the Performance of Automotive Radiator at Higher Coolant Temperature", Journal of Basic and Applied Engineering Research, Volume 1, Number 3.

[13] Chavan D. K and Tasgaonkar G. S, (2013) "Study, Analysis and Designof Automobile Radiator (Heat Exchanger) Proposed with Cad Drawings and Geometrical Model of the Fan", International Journal of Mechanical and Production Engineering Research and Development, Vol. 3, Issue 2. 